\title{
Cytogenetic Studies in Avena, IX New Synthetic Oats in the Progenies of Induced Decaploid Interspecific Hybrids ${ }^{1)}$
}

\author{
Ichizo NishiYama \\ Faculty of Agriculture, Kyoto University
}

Received November 11, 1961

In the genus Avena was found a polyploidy consisting of multiples of seven chromosomes and the genome formulae AA, AAB' $\mathrm{B}^{\prime}$ (Nishiyama 1934, 1936) and AABBCC (Huskins 1927) were given to diploid, tetraploid and hexaploid species respectively. From their observation on the karyotype of Avena species Rajhathy and Morrison (1959) proposed that the hexaploid oats genomes should be AACCDD. Although the different symbols represent different genomes an occasional occurrence of unexpected meiotic pairing of chromosomes in interspecific hybrids disclosed partial homology of these genomes. That is, in triploid hybrids $(2 n=21)$ between diploid and tetraploid species the frequency of paired chromosomes, including bivalents and multivalents was $76.76 \%$ (66.67\% expected on the basis of calculation from the genome formula mentioned above). On the other hand, the percentage of paired chromosomes was 47.76 ( 50.00 calculated) in tetraploid hybrids $(2 n=28)$ between hexaploid and diploid species, and 45.56 (80.00 calculated) in pentaploid hybrids between tetraploid and hexaploid species (Nishiyama 1929, 1934; Kihara and Nishiyama 1932) (Table 1). Thus the weakest affinity of chromosomes was observed in pentaploid hybrids. It is sometimes stated that the fewer the number of paired chromosomes in interspecific hybrids the higher the fertility in their amphiploids induced by doubling chromosomes. Based on this fact the author produced decaploid and hexaploid oats by doubling chromosomes of pentaploid and triploid hybrids respectively and made a comparative observation on the seed fertility, growth, breeding behavior etc. in these artificial amphiploids. As was expected induced hexaploids showed a low fertility or very variable fertility and a wide variation of plant growth generation after generation. It is very difficult to get a strain which breeds true as yet. On the contrary a high fertility was found in some strains in the progeny of decaploid oats. It is especially noted that these decaploids segregated many strains differing in plant characters and having 42, 46, 56 chromosomes $(2 \mathrm{n})$, etc. in later generations. Some of them appear to be much improved use as forage crops or grain crops. In this paper is presented an outline of studies on the progeny of induced decaploids, with special emphasis on increase in seed fertility.

1) Contribution from the Laboratory of Genetics, Faculty of Agriculture, Kyoto University, Japan, No. 294. The study was supported partly by grants from the Scientific Research Fund of the Ministry of Education. 
Table 1. Frequency of paired chromosomes at MI in interspecific Avena hybrids

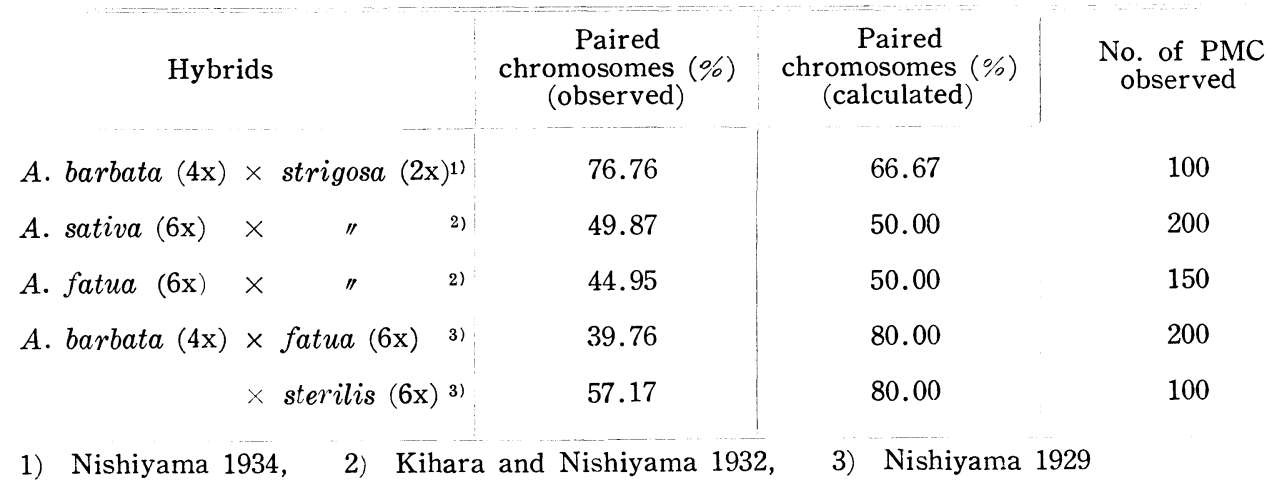

\section{Material and Methods}

It is a major subject to transfer economical characters of tetraploid oats into hexaploids ( $A$. sativa and $A$. nuda). The tetraploid species $A$. barbata and $A$. abyssinica and a line $\mathrm{T}_{t}-1$ derived from a triploid hybrids between $A$. barbata and $A$. strigosa were used as tetraploid parent. A. barbata is especially characterized by its tremendous number of tillers and by a long term of tillering period. A. abyssinica shows desirable characters of early maturity and short plant height, but the undesirable characters of viviparity. $\mathrm{T}_{t}-1$ looks similar to $A$. barbata, but is more vigorous.

Pentaploid $F_{1}$ seedlings were treated with $0.05 \%$ colchicine solution in the fall of 1948 and 1950. The base of the culm of young pentaploid $F_{1}$ seedlings was cut longitudinally as that the colchicine solution could be applied to the growing stem tip. Pentaploid hybrids were highly sterile and often completely sterile. However, some of the colchicine treated hybrids produced all fertile panicles; others produced some culms with fertile panicles. Such fertility might be attributed mainly to doubling chromosomes in pentaploid hybrids. Their seeds were harvested and they gave rise to progenies in the following generations.

\section{Seed fertility of pentaploid hybrids treated with colchicine}

Some young seedlings of $A$. abyssinica $\times$ sativa were treated with $0.05 \%$ colchicine solution in 1948 . In 1950 seedlings of $A$. barbata $\times A$. sativa, A. barbata $\times A$. nuda and $\mathrm{T}_{t}-1 \times A$. sativa were also treated with $0.05 \%$ colchicine solution. Comparable results were obtained in both experiments, that is, a smaller number of plants survived. Table 2 shows the results only of the 1950 experiment. These treated pants showed a wide variation in seed fertility in different individuals and even in different panicles of the same plant in contrast with the report of Nishiyama (1929), that is all of the pentaploid hybrids set few or no seeds, less than $1 \%$. Accordingly the author counted the number of seeds on each panicle in some of the plants, and a part of the results, excepting especially most of non-fertile plants are given in Table 3. Panicles could be classified into three groups, high, medium and low or zero per- 
Table 2. Colchicine treatment of young seedlings of pentaploid hybrids in 1950

\begin{tabular}{|c|c|c|c|c|c|c|c|}
\hline & \multirow{2}{*}{\multicolumn{3}{|c|}{ Hybrids }} & \multirow{2}{*}{$\begin{array}{c}\text { No. of seedlings } \\
\text { treated }\end{array}$} & \multicolumn{3}{|c|}{ No. of plants survived } \\
\hline & & & & & $2 n$ & $2 n-4 n$ & $4 \mathrm{n}$ \\
\hline 1. & A. barbata & $x$ & nuda (98) & 13 & 1 & 1 & 0 \\
\hline 2. & " & $x$ & sativa (Aurora) & 15 & 0 & 1 & 0 \\
\hline 3. & $" \prime$ & $x$ & " (Banner) & 21 & 8 & 0 & 1 \\
\hline 4. & $"$ & $x$ & " (Mutica) & 5 & 0 & 0 & 0 \\
\hline 5. & $n$ & $x$ & $"$ (Victory) & 13 & 2 & 1 & 1 \\
\hline 6 & " (23) & $\times$ & $"$ & 24 & 0 & 2 & 1 \\
\hline 7. & $\mathrm{~T}_{t^{-1}}$ & $x$ & " (Banner) & 28 & 2 & 3 & 0 \\
\hline 8. & $"$ & $x$ & " (Mutica) & 17 & 0 & 0 & 0 \\
\hline 9. & $" \prime$ & $x$ & " (Victory) & 20 & 0 & 0 & 0 \\
\hline
\end{tabular}

centage of fertility. It was ascertained by cytological researches on the progenies that the high, medium and low fertility groups are associated with $4 n, 2 n-4 n$ chimera, and $2 \mathrm{n}$ panicles, respectively (Table 2 ). Out of 24 hybrids only three produced all amphiploid panicles $(4 \mathrm{n})$. Some plants showed mixoploid of $2 \mathrm{n}$ and $4 \mathrm{n}$. Mixoploid consisted of various degrees of $2 \mathrm{n}$ and $4 \mathrm{n}$ parts, e.g., $2 \mathrm{n}$ and $4 \mathrm{n}$ panicles in a plant, $2 \mathrm{n}-4 \mathrm{n}$ tissue in a panicle or culm. In 13 plants with low ferility colchicine treatment probably failed to double the number of chromosomes.

\section{Breeding behavior in the progeny of amphiploid oats}

All plants from one panicle $\left(\mathrm{C}_{1}\right.$-panicle $)$ of colchicine treated hybrids were treated as one $\mathrm{C}_{2}$-line. Many $\mathrm{C}_{2}$-lines were grown from $\mathrm{C}_{1}$-panicles which showed different fertilities under open pollination in $\mathrm{C}_{1}$-plants. Correct chromosome numbers were often hardly countable in $\mathrm{C}_{2}$-plants, because of complex associations and high chromosome numbers. However, doubling of chromosomes in pentaploid hybrids was easily assumed in plants so far examined as shown in Table 2. These $\mathrm{C}_{2}$-plants although in the same line, were widely different in plant morphology, seed fertility and probably in chromosome number. In order to study the breeding behavior of decaploid progenies, pedigree method was tried in the following generations. It is especially noteworthy that these decaploid amphiploids did not breed true, varying in plant characters and seed fertility. Consequently the author made selections of certain plant characteristics and high fertility in succeeding generations.

The seed fertility was usually investigated in two or more panicles from each of three or more plants in each line. A part of the results is shown in Table 4 in which numbers represent the seed fertility (\%) or the range in fertility in each line. The author found two remarkable tendencies regarding the change of fertility in successive 
Table 3. Fertility of some plants $\left(\mathrm{C}_{1}\right)$ treated with colchicine

\begin{tabular}{|c|c|c|c|c|c|c|c|c|c|}
\hline \multicolumn{5}{|c|}{ Individual No. of hybrids } & Culm No. & $\begin{array}{l}\text { No. of } \\
\text { spikelets }\end{array}$ & $\begin{array}{l}\text { No. of } \\
\text { florets }\end{array}$ & $\begin{array}{l}\text { No. of } \\
\text { kernels }\end{array}$ & $\begin{array}{c}\% \text { of } \\
\text { kernels }\end{array}$ \\
\hline 1. & A. barbata & $x$ & A. nuda (98) & -2 & $\begin{array}{l}1 \\
2 \\
3 \\
4 \\
5 \\
6\end{array}$ & $\begin{array}{l}85 \\
98 \\
63 \\
54 \\
70 \\
40\end{array}$ & $\begin{array}{r}166 \\
191 \\
120 \\
108 \\
140 \\
79\end{array}$ & $\begin{array}{r}0 \\
5 \\
7 \\
103 \\
133 \\
38\end{array}$ & $\begin{array}{r}0.00 \\
2.62 \\
5.83 \\
95.37 \\
95.00 \\
48.10\end{array}$ \\
\hline 2. & A. barbata & $\times$ & A. sativa (Aurora) & & $\begin{array}{l}1 \\
2 \\
3\end{array}$ & - & $\begin{array}{r}9 \\
21 \\
53\end{array}$ & $\begin{array}{r}8 \\
13 \\
0\end{array}$ & $\begin{array}{r}88.89 \\
61.90 \\
0.00\end{array}$ \\
\hline \multirow[t]{2}{*}{3.} & A. barbata & $x$ & A. sativa (Banner) & -1 & $\begin{array}{l}0 \\
1 \\
2 \\
3\end{array}$ & $\begin{array}{l}75 \\
57 \\
63\end{array}$ & $\begin{array}{l}145 \\
114 \\
126\end{array}$ & $\begin{array}{l}3 \\
0 \\
2\end{array}$ & $\begin{array}{l}2.08 \\
0.00 \\
1.59\end{array}$ \\
\hline & & & & -2 & $\begin{array}{l}1 \\
2 \\
3\end{array}$ & $\begin{array}{l}44 \\
23 \\
37\end{array}$ & $\begin{array}{l}88 \\
44 \\
73\end{array}$ & $\begin{array}{l}80 \\
35 \\
59\end{array}$ & $\begin{array}{l}90.91 \\
79.55 \\
80.82\end{array}$ \\
\hline \multirow[t]{2}{*}{4.} & A. bxrbata & $x$ & A. sativa (Victory) & -2 & $\begin{array}{l}1 \\
2 \\
3\end{array}$ & $\begin{array}{l}68 \\
19 \\
27\end{array}$ & $\begin{array}{r}122 \\
31 \\
35\end{array}$ & $\begin{array}{r}2 \\
6 \\
27\end{array}$ & $\begin{array}{r}1.64 \\
19.35 \\
77.71\end{array}$ \\
\hline & & & & -4 & $\begin{array}{l}1 \\
2 \\
3 \\
4 \\
5 \\
6 \\
7\end{array}$ & $\begin{array}{r}102 \\
29 \\
94 \\
81 \\
50 \\
70 \\
76\end{array}$ & $\begin{array}{r}194 \\
52 \\
178 \\
162 \\
\longleftarrow 8 \\
124 \\
141\end{array}$ & $\begin{array}{r}168 \\
34 \\
154 \\
140 \\
90 \\
91 \\
127\end{array}$ & $\begin{array}{l}86.60 \\
65.38 \\
88.02 \\
86.42 \\
91.84 \\
73.39 \\
90.07\end{array}$ \\
\hline \multirow[t]{2}{*}{5.} & A. barbata & & A. sativa (Victory) & & $\begin{array}{l}1 \\
2 \\
3 \\
4 \\
5\end{array}$ & $\begin{array}{l}30 \\
53 \\
61 \\
46 \\
36\end{array}$ & $\begin{array}{r}60 \\
103 \\
118 \\
92 \\
62\end{array}$ & $\begin{array}{r}36 \\
82 \\
100 \\
4 \\
1\end{array}$ & $\begin{array}{r}60.00 \\
79.61 \\
84.75 \\
4.35 \\
1.61\end{array}$ \\
\hline & & & & -2 & $\begin{array}{l}1 \\
2 \\
3 \\
4 \\
5\end{array}$ & $\begin{array}{l}82 \\
75 \\
91 \\
69 \\
98\end{array}$ & $\begin{array}{l}164 \\
150 \\
179 \\
139 \\
191\end{array}$ & $\begin{array}{r}81 \\
105 \\
143 \\
93 \\
82\end{array}$ & $\begin{array}{l}49.39 \\
70.00 \\
79.89 \\
66.91 \\
42.93\end{array}$ \\
\hline \multirow[t]{2}{*}{6.} & $\mathrm{~T}_{t}-1$ & $x$ & A. sativa (Banner) & -1 & $\begin{array}{l}1 \\
2 \\
3 \\
4 \\
5\end{array}$ & $\begin{array}{r}61 \\
94 \\
109 \\
57 \\
119\end{array}$ & $\begin{array}{l}112 \\
172 \\
196 \\
114 \\
238\end{array}$ & $\begin{array}{r}81 \\
36 \\
108 \\
4 \\
1\end{array}$ & $\begin{array}{r}71.07 \\
20.93 \\
55.10 \\
3.51 \\
0.42\end{array}$ \\
\hline & & & & -3 & 1 & 60 & 120 & 8 & 6.67 \\
\hline
\end{tabular}

generations. (1) In general fertility increases generation after generation and reaches a level nearly as high as the normal fertility. (2) However, in some lines fertility varied widely without continuous trend toward increasing fertility. The latter tendency can be seen in the progeny of the cross between $A$. abysinica (24) and A. sativa var. Aurora, and some lines in the other crosses. It is very interesting to know that in the same type of cross, involving $A$. abyssinica (25) instead of $A$. abyssinica (24), progenies of high fertility were obtained. Both abyssinica variaties have similar 


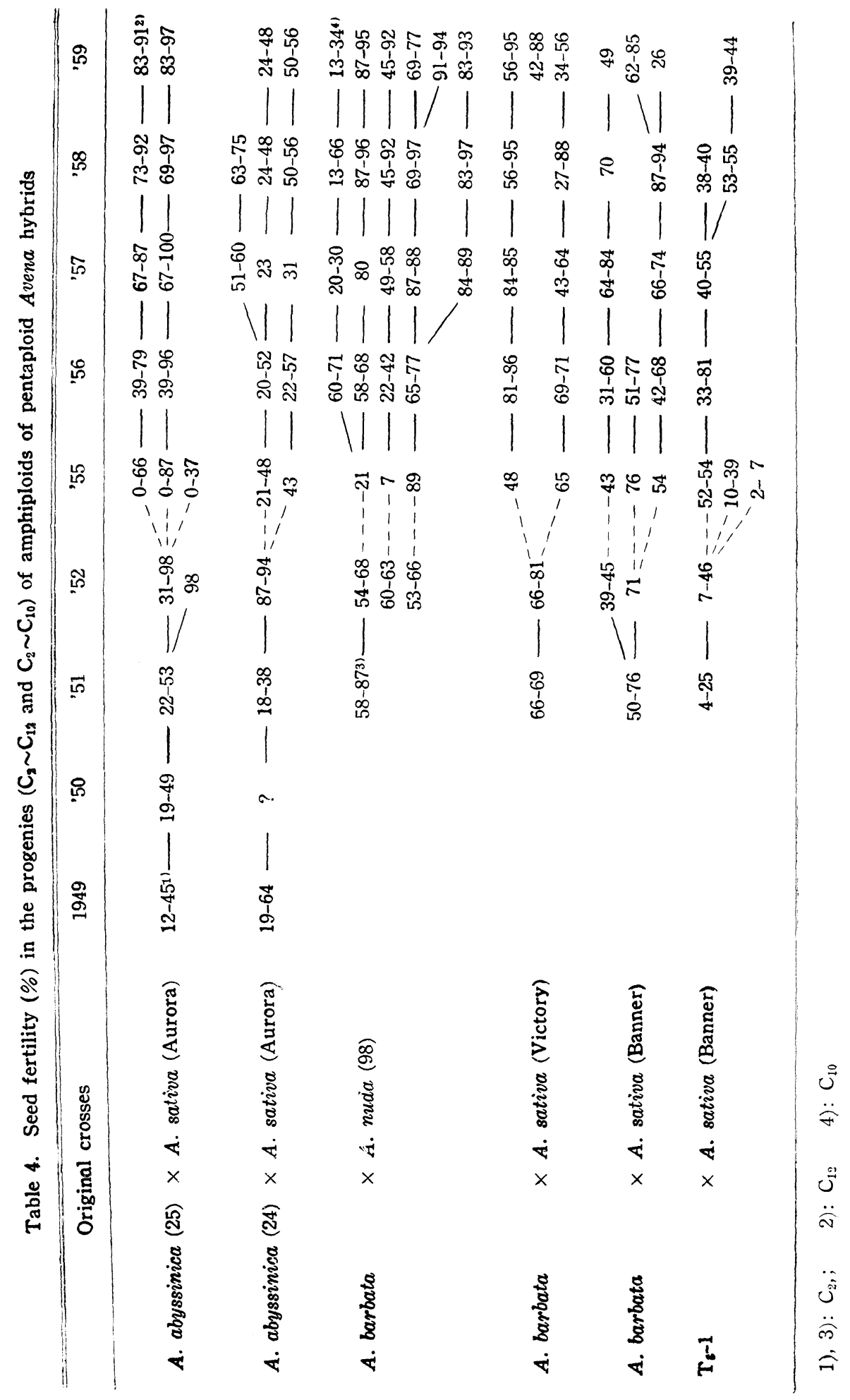


characteristics, except that No. 24 has dark brown grains and No. 25 gray grains. It is especially noted here that some strains from crosses involving $A$. abyssinica (25) as one of the parents set large and plump seeds which are never seen in any variety of oats.

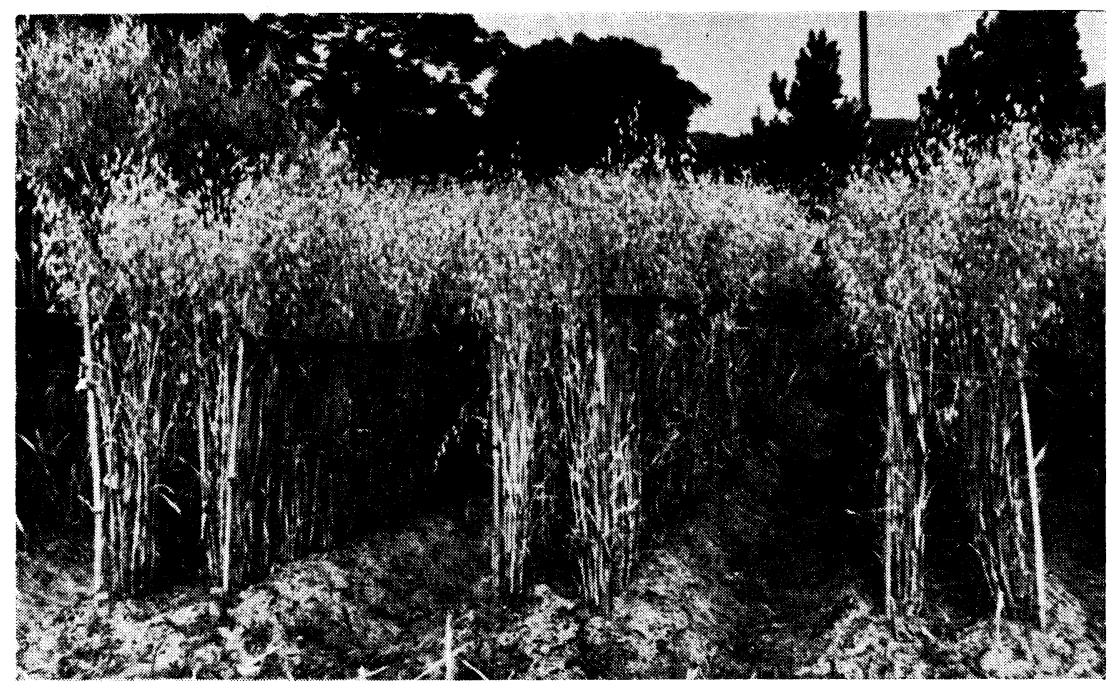

Fig. 1. Some synthetic oats $(8 \mathrm{x})$ lines $(60-5012 \sim 5017$, from right to left) in the progeny of amphiploids of the hybrid, A. abyssinica $(4 \mathrm{x}) \times A$. sativa Aurora $(6 \mathrm{x})$.

Outline of morphology and cytology of the synthetic oats

In the progenies of six different amphiploids induced from interspecific pentaploid Avena hybrids there have been obtained many lines which differ in growth habit and morphological characters. Details of their characteristics will be reported in the future. In this section are given only brief results of morphological and cytological observations on some representative lines $\left(\mathrm{C}_{9} \sim \mathrm{C}_{13}\right)$, including highly true-breeding and nontrue-breeding forms. About 25 plants were grown in each line and five picked out on the basis of their normal growth were employed for observations on their characteristics.

\section{Plant height}

Plants spaced $10 \sim 15 \mathrm{~cm}$ were grown in rows $130 \mathrm{~cm}$ apart. These plants grew very well and observations were chiefly made at the time of harvest. The plant height means the total length of culm and panicle. The plant height was calculated by taking the average of five culms and panicles from five plants selected in each line. Only the single longest and fully developed culm per plant was measured.

As shown in Table 5 nearly all of progenies derived from A. abyssinica $\times A$. sativa var. Aurora were shorter than the control (A. sativa var. Banner) and other synthetic oats. This characteristics might be due to the shortness of both parents. In other 
Table 5a. Frequency distribution of a number of synthetic oat lines from interspecific Avena hybrids according to average length of culms

Original crosses

A. abyssinica $(25) \times$ A. sativa Aurora (24)

A. barbata $\times \quad$ A. nuda (98)

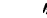

H

$\mathrm{T}_{t-1}$

A. sativa Banner (control)
Length of culms, $\mathrm{cm}$

$\begin{array}{lllllll}75 & 85 & 95 & 105 & 115 & 125 & 135\end{array}$

$12 \quad 2 \quad 2$

$\begin{array}{llll} & 7 & 2 & 5 \\ 1 & & 5 & 1 \\ 3 & 2 & 8 & 1 \\ & & 1 & 2\end{array}$

1

Table 5b. Frequency distribution of a number of synthetic oat lines from interspecific Avena hybrids according to average length of panicles

\begin{tabular}{|c|c|c|c|c|c|c|}
\hline \multirow{2}{*}{\multicolumn{3}{|c|}{ Original crosses }} & \multicolumn{4}{|c|}{ Length of panicles, $\mathrm{cm}$} \\
\hline & & & 25 & 30 & 35 & 40 \\
\hline A. abyssinica (25) & $\times$ & A. sativa Aurora & 2 & 2 & & \\
\hline$(24)$ & $x$ & $"$ & 3 & 2 & & \\
\hline A. barbata & $x$ & A. $n u d a(98)$ & & 2 & 8 & 3 \\
\hline$"$ & $x$ & A. sativa Banner & & 1 & 3 & 3 \\
\hline$"$ & $x$ & A. sativa Victory & & 6 & 6 & 2 \\
\hline$T_{t}-1$ & $\times$ & A. sativa Banner & & & & 3 \\
\hline \multicolumn{3}{|c|}{ A. sativa Banner (control) } & \multicolumn{4}{|c|}{1} \\
\hline
\end{tabular}

Table 5c. Frequency distribution of a number of synthetic oat lines from interspecific Avena hybrids according to average plant height

\begin{tabular}{|c|c|c|c|c|c|c|c|c|c|}
\hline \multirow{2}{*}{\multicolumn{2}{|c|}{ Original crosses }} & \multicolumn{7}{|c|}{ Plant height, inclusive of culms \& panicles, } & \multirow{2}{*}{$\frac{\mathrm{m}}{175}$} \\
\hline & & 105 & 115 & 125 & 135 & 145 & 155 & 165 & \\
\hline \multicolumn{2}{|c|}{ A. abyssinica $(25) \times A$. sativa Aurora } & & 2 & & 2 & & & & \\
\hline$(24)$ & $\times \quad " \prime$ & 3 & 1 & 1 & & & & & \\
\hline A. barbata & $\times A . n u d a(98)$ & & 1 & & & 5 & 3 & 1 & 4 \\
\hline$"$ & $\times A$. sativa Banner & & & & & 1 & 1 & 4 & 1 \\
\hline$"$ & $\times A$. sativa Victory & & & & 3 & 1 & 7 & 2 & 1 \\
\hline $\mathrm{T}_{t}-1$ & $\times A$. sativa Banner & & & & & & & 1 & 3 \\
\hline \multicolumn{2}{|c|}{ A. sativa Banner (control) } & & & & & & 1 & & \\
\hline
\end{tabular}


synthetic oats, plants were shorter or taller than those of $A$. sativa var. Banner (control). Thus there were obtained many oat forms showing a wide range of plant height from 105 to $175 \mathrm{~cm}$.

\section{Tillering}

The average number of culms per plant which produced normal panicles in each line is given in Table 6 . In most lines the synthetic oats tillered more profusely than the control, in some cases producing more than three times the number of tillers in the control. This fact is suggestive of their vigorous growth. These plants were grown under the standard field conditions, enriched normally by fertilizer. When they were grown in soil of low fertility, being short in fertilizer, the plants produced a small number of tillers. The extent of tillering in oats is governed by internal genetical peculiarities of the plants and also by various external causes. In some cases late forms usually produce many tillers and early forms few tillers.

Table 6. Frequency distribution of a number of synthetic oat lines from interspecific Avena hybrids according to average number of culms per plant

Original crosses

$\begin{array}{ccc}\text { A. abyssinica (25) } & \times & \text { A. sativa Aurora } \\ \text { " (24) } & \times & " \\ \text { A. barbata } & \times & A . \text { nuda (98) } \\ \text { " } & \times & \text { A. sativa Banner } \\ \text { " } & \times & \text { A. sativa Victory } \\ \mathrm{T}_{t}-1 & \times & \text { A. sativa Banner }\end{array}$

A. sativa Banner (control)
No. of culms

\begin{tabular}{lllllllll}
11 & 16 & 21 & 26 & 31 & 36 & 41 & 46 \\
\hline
\end{tabular}

$\begin{array}{llllllll}1 & 1 & & 2 & & & & \\ & 2 & & 1 & 2 & & & \\ & 2 & 4 & 4 & 3 & 1 & & \\ & 1 & 4 & 1 & & 1 & & \\ & 5 & 4 & 2 & & 1 & 1 & 1 \\ & & 2 & 1 & & & & \end{array}$

1

3. Ripening date

One of the parents, A. barbata, is an early form but it is rather characterized by its long tillering period so that some panicles are ripening while the others are still flowering or heading. This barbata character was found in a few synthetic progenies although it was not as remarkable as in A. barbata itself. There also was found another type of growth habit. Some strains segregated early, late, and very late ripening plants. The very late ripening plants usually failed to produce panicles until the end of July or later and in such cases the plants died as a consequence of vegetative growth inhibited by high temperature or other environment factors.

Generally speaking there can be seen a close relationship between the time of heading and that of maturity in oat varieties, $i$.e., early heading varieties are rather early ripening and late heading ones are late ripening. $A$. abyssinica is the earliest maturing species and $A$. sativa var. Aurora is earlier than any other hexaploid variety 
used. All progenies of their hybrids were very early, probably owing to the earliness of both parents. Other synthesized oats from different original hybrids showed different ranges of ripening time.

Table 7. Dates of ripening of a number of synthesized oats lines* from some interspecific Avena hybrids.

\begin{tabular}{|c|c|c|c|c|c|c|c|c|c|c|c|}
\hline \multirow{2}{*}{\multicolumn{3}{|c|}{ Original crosses }} & \multicolumn{6}{|c|}{ June } & \multicolumn{3}{|c|}{ July } \\
\hline & & & 3 & 8 & 13 & 18 & 23 & 28 & 3 & 8 & in 1959 \\
\hline A. abyssinica & $(25)$ & $\times$ A. sativa Aurora & 7 & 1 & 2 & & & & & & \\
\hline " $\quad(24)$ & $x$ & $"$ & & & & 4 & & & & & \\
\hline A. barbata & $x$ & A. nuda (98) & & 3 & 17 & 0 & 9 & & & & \\
\hline " & & A. sativa Banner & & & 2 & 5 & 2 & 1 & & & \\
\hline$"$ & & A. sativa Victory & & & & & 8 & 2 & 0 & & 4 \\
\hline $\mathrm{T}_{t}-1$ & & A. sativa Banner & & & & & 1 & 2 & & & \\
\hline A. sativa $\mathrm{Ba}$ & ner & (control) & & & & & & 1 & & & \\
\hline
\end{tabular}

* These oats were sown in nursery early Nov. and transplated in the field Dec. in 1958.

\section{Chromosome number}

Synthetic oats refer to the artificial decaploids obtained from doubling chromosome numbers of pentaploid hybrids. Meiotic pairing of chromosomes in PMC of these decaploids were very complicated. This cytological study and the wide variation observed in plant characters during the period of pedigree culture suggested that these amphiploids were neither constant in genetic characters nor in the chromosome number. Throughout the period of selection based on plant morphology and high fertility, however, the pedigree culture was performed for many generations without any artifical selection of their chromosome numbers. The chromosome count was first made on $\mathrm{C}_{9}$ or $\mathrm{C}_{12}$ progenies. Out of numerous lines, some of which were highly constant and the others inconstant, were used for cytological investigations.

As shown in Table 8 two lines possess 42 chromosomes, two 54 chromosomes, two 56 chromosomes and one 58 chromosomes. In these cases meiotic pairing of chromosomes was normal or nearly normal although the occurrence of some univalents or chromosome complexes was occasionally found. In other lines no constant chromosome numbers were observed, e.g., plants from line 60-5005 possessed $2 n=54$ and 56 although morphological differences between them were hardly recognizable. In two lines, 60-5116 and 60-5136, their heterozygosity was easily recognized by the segregation of plants with different morphology or growth habits. For example, the line 605116 segregated midseason heading type and an extraordinarily late type which often failed to produce any seeds in the season. In these lines three different chromosome numbers, $2 \mathrm{n}=53,54$, and 56 , were counted and the chromosome pairing was also unstable. In short $\mathrm{C}_{9}-\mathrm{C}_{12}$ progenies of decaploid amphiploids were found to be usually 
Table 8. Chromosome numbers in the progenies of induced decaploids $(2 n=70)$ from interspecific Avena hybrids $(2 \mathrm{n}=35)$

\begin{tabular}{|c|c|c|c|c|}
\hline \multicolumn{2}{|c|}{ Original crosses } & Line No. & $2 n$ & $\begin{array}{l}\% \text { of } \mathrm{PMC} \\
\text { with } 27 \mathrm{II} \text {, } \\
28 \mathrm{II} \text { or } 29_{\mathrm{II}}^{*}\end{array}$ \\
\hline \multirow{3}{*}{\multicolumn{2}{|c|}{ A. abys. (25) $\times$ A. sat. Aurora }} & $60-5003$ & $56(4) * *$ & 62.2 \\
\hline & & -5005 & $54(2), 56(2)$ & 50.4 \\
\hline & & -5017 & $55(1), 56(3)$ & 63.3 \\
\hline \multirow[t]{4}{*}{ A. barb. } & $\times$ A. nuda (98) & -5029 & $55+f(1), 56(1), 56+f(1), 57(1), 58(3)$ & 32.3 \\
\hline & " & $-503 t$ & $42(8)$ & 93.5 \\
\hline & " & -5057 & $56(6)$ & 65.4 \\
\hline & $" \prime$ & -5066 & $58(6)$ & 46.5 \\
\hline \multirow[t]{3}{*}{ A. barb. } & $\times$ A. sat. Banner & -5080 & $42(10)$ & 97.9 \\
\hline & " & -5083 & $50-51(1), 50(1), 51(2), 52(2), 50-53(1)$ & - \\
\hline & $"$ & -5088 & $55(2), 56(4)$ & 33.0 \\
\hline \multirow[t]{3}{*}{ A. barb. } & $\times$ A. sat. Victory & -5101 & $53(1), 56(6)$ & 45.2 \\
\hline & $"$ & $-5116 * * *$ & $53(1), 54(2), 56(7)$ & 21.2 \\
\hline & $"$ & $-513 \epsilon$ & ๖3(1), 54(1), 56(7) & 39.4 \\
\hline \multirow[t]{2}{*}{$\mathrm{T}_{t}-1$} & $\times$ A. sat. Banner & -5151 & $54(3)$ & 71.1 \\
\hline & $"$ & -5154 & $54(5)$ & 60.7 \\
\hline
\end{tabular}

* Only in plants with $2 \mathrm{n}=54,56$ and 58 chromosomes were counted the frequency of PMC-s possessing $27_{\mathrm{II}}, 28_{\mathrm{II}}$ and $29_{\mathrm{II}}$ respectively.

** The number within parentheses shows the number of plants examined cytologicaly.

*** Some segregates were so late that then could not produce panicles in the growing season.

octoploids and sometimes hyper- or hypo-octoploids as well as hexaploids. In hexaploid derivatives were observed the most stable pairing of chromosmes at meiosis. Details of cytological studies will be reported in the future. The analysis of chromosome constitution in these synthetic oats is under investigation.

\section{Discussion}

It is generally understood that amphiploids induced from interspecific hybrids are fertile and breed true, but this was not usually true of the decap'oid amphiploid oats. Morphology, fertility, and chromosome number in the decaploids were found to be very variable especially in the early generations. These unexpected characteristics of these amphiploids could mainly be brought about by irregular behavior of meiotic chromosomes. The genome constitution of decaploid amphiploid oats can be represented by the formula of $A A A A B B B^{\prime} B^{\prime} C C$ in which $A A B^{\prime} B^{\prime}$ are contributed by the tetraploid parent and $\mathrm{AABBCC}$ by the hexaploid parent. As previously mentioned $\mathrm{A}$ is partially homologous with $B$ and probably with $B^{\prime}$. Thus these octoploid amphiploids 


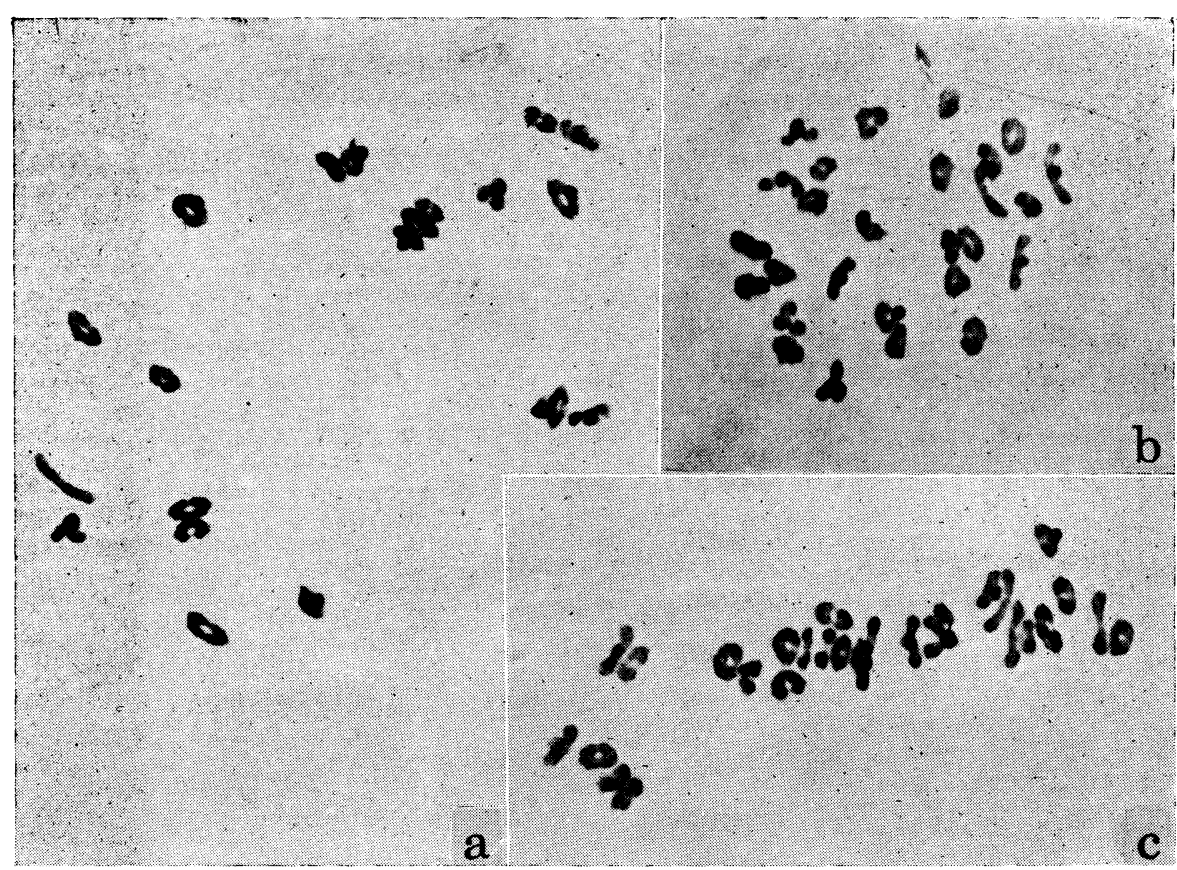

Fig. 2. Meiotic chromosomes at $\mathrm{MI}$ in PMC of some synthetic oats.

a, 21II, two bivalents being overlapped (Plant No. 60-5080-8), b, 27 II (Plant No. 60-5151-12), c, 28 II (Plant No. 60-5136-24).

are neither autoploids nor alloploids but are rather the so-called segmental alloploids. Accordingly meiotic pairing of chromosomes in their pollen mother cells were very complicated by the formation of multivalents or univalents, and the large number of chromosomes $(2 \mathrm{n}=70)$.

It is interesting to know that their progenies in the later generations $\left(\mathrm{C}_{9} \sim \mathrm{C}_{12}\right)$ can be divided into two groups according to their chromosome numbers. One group has 42 chromosomes $(2 \mathrm{n})$ and the other 56 or $56 \pm$ chromosomes. The former generally shows a regular formation of 21 bivalents and their meiotic behavior is quite normal. In a number of progeny lines, plants with 56 or $56 \pm$ chromosomes also indicate high stability in the chromosome constitution although occasionally meiotic irregularities are observed. At any rate it can be said that these chromosome constitutions are in balance for performing their biological function. It is very important to know the chromosomal relationship between these synthetic oats and their parental species. This problem is now under investigation and the result will be reported in the following paper.

Pentaploid Avena hybrids are completely or highly sterile (Nishiyama 1929). Doubling their chromosome number makes them highly fertile. This feature is quite similar to that of usual induced amphiploids which are generally able to retain high fertility. In the synthesized oats fertility varied widely from complete sterility to high fertility in the succeeding generations and their variability was especially prevalent in the early generations. From the $\mathrm{C}_{9} \sim \mathrm{C}_{12}$ generations, certain lines kept their high fertility 
but others did not. Highly fertile lines are usually hexaploid and octoploid, including hyper or hypo-octoploid, and their meiotic behavior of chromosomes is regular. Besides the number of chromosomes, the functional balance of chromosome components seems to be necessary for maintaining high fertility. A. sativa var. Banner $(2 n=42)$ used as control showed medium fertility (66\%) in Kyoto. This fertility might be affected by environmental conditions, especially high temperature at the flowering season as it has a slow growing habit. The same feature can be seen in a number of late varieties of synthesized oats.

These synthetic oats are new plants possessing a number of characters from both tetraploids, wild or cultivated types, and cultivated hexaploids. In general they gave many types different from their parents and showed a wide variation in their characters. For example, certain lines showed some of these characters, earliness, vigor, high tillering ability, high yield as green fodder, resistance to aphis, big grain, etc. which are important economical characters for breeding commercial oats. Some synthesized lines are likely to be much improved, especially for use as green fodder. On the other hand, most of these lines could be employed as bridge varieties to transfer some characters of tetraploids to hexaploids in the advancement of oats breeding.

Many years ago the author made cytogenetical investigations of the progenies of pentaploid oats, A. barbata $\times$ fatua and $A$. barbata $\times$ sativa. A comparison of the previous and current investigations indicates that the method of the present study appears to be more applicable for successful oats breeding than the previous study. Besides the induction of decaploid amphiploids the author tried to produce an artificial hexaploid form by doubling chromosomes in triploid hybrids between $A$. abyssinica $(2 \mathrm{n}=$ $28)$ and $A$. strigosa $(2 \mathrm{n}=14$ '. However it is very difficult to get improved strains since many are inferior in fertility, vigor, and true breeding and have other undesirable characteristics.

Considering these studies mentioned above, an investigation of amphiploids induced from interspecific tetraploid hybrids between hexaploid and diploid oats appears to be very interesting. In this case it is not easy to get tetraploid $F_{1}$ hybrids which can only be obtained when hexaploid oats are used as mother plant.

A review of the methods or ideas for the improvement of common oats by utilizing genes from lower polyploids discloses the interesting study reported by Zillinsky and Derick (1960) who succeeded in directly transfering disease resistance of $A$. strigosa $(4 \mathrm{n})$ in $A$. sativa in progenies of their interspecific hybrids. Besides, other approaches have been attempted by Brown and Shands (1954), Zillinsky, Sadanaga, Simons and Murphy (1959) as well as Sadanaga and Simons (1960). Thus there will be presented many methods and ideas for employing the wild species or lower polyploid species for the improvement of common oats. 


\section{Summary}

For the pentaploid hybridization, Avena barbata, A. abyssinica and $\mathrm{T}_{t}-1$ (a barbata like derivative from triploid hybrids, $A$. barbata $\times A$. strigosa) were used as tetraploid parents and certain varieties of $A$. sativa and $A$. nuda as hexaploid ones. Young seedlings of the pentaploid hybrids were treated with $0.05 \%$ colchicine solution and their chromosome number was successfully doubled in some of them, producing decaploid amphiploids or chimera plants consisting of pentaploids and decaploids.

Decaploid plants or panicles $\left(\mathrm{C}_{1}\right)$ showed high seed fertility although the pentaploid ones set usually no seeds. Decaploids amphiploids, however, failed to maintain their high seed fertility. In $\mathrm{C}_{8} \sim \mathrm{C}_{12}$ generations, however, some amphiploid lines recovered fertility equal to the original parents but other lines still showed low or wide variation in fertility.

Cytological investigations were attempted with certain lines in $\mathrm{C}_{9} \sim \mathrm{C}_{13}$. It is especially noted that certain lines have $2 n=42,54,56$, or 58 , instead of the expected chromosome number, $70(2 \mathrm{n})$ and those lines show regular meiotic behavior of chromosomes. In the other lines the chromosome number varied over a limited range (2-4) and still others over a wide range (4-8).

Some characters such as plant height, tillering, and date of maturity were studied and compared with one of the parents, A. sativa var. Banner. Most of these synthetic oats are new forms possessing some characters from both tetraploid and hexaploid parents, and are much improved in certain agronomic characters.

\section{Literature cited}

Brown, C. M. and H. L. Shands 1954 Behavior of the interspecific hybrid and amphiploid of Avena abyssinica $\times$ A. strigosa. Agron. Jour. 46: 557-559.

Huskins, C. L. 1927 Genetical and cytological studies of fatuoid oats and speltoid wheats. V. Inter. Kongr. Vererbungswissensch. Zeits. Induk. Abst. u. Vererb. Supp. 11: 907-916.

, G. F. Sander and R. M. Love 1939 Chromosome aberrations as the cause of fatuoid, steriloid and subfatuoid mutations in oats. Seventh Inter. Cong. Genet., Edinburgh.

Nishiyama, I. 1929 The genetics aná cytology of certain cereals, I. Morphological and cytological studies on triploid, pentaploid and hexaploid Avena hybrids. Jap. Jour. Genet. 5: 1-48. 1932 Idem, III. Kihara H. and Nishiyama, I. Different compatibility in reciprocal crosses of Avena, with special reference to tetraploid hybrids between hexaploid and diploid species. Jap. Jour. Bot. 6: 245-305.

1934 Idem, VI. Chromosome behavior and its bearing on inheritance in triploid Avena hybrids. Mem. Coll. Agri., Kyoto Imp. Univ. No. 32: 1-157.

1951 Artificial amphidiploids of pentaploid oats hybrids. Jap. Jour. Breeding 1: 91-94.

Rajhathy, T. and J. W. Morrison 1959 Chromosome morphology in the genus Avena. Canad. Jour. Bot. 37: 331-337.

Sadanaga, K. and M. D. Simons 1960 Transfer of brown rust resistance of diploid and tetraploid species into hexaploid oats. Agron. Jour. 52: 285-288.

Zillinsky, F. J. and R. A. Derick 1960 Crown rust resistant derivatives from crosses between autotetraploid Avena strigus $\iota$ and A. sativa. Canad. Jour. Plant Sci. 40: 366-370.

, K. Sadanaga, M. D. Simons and H. C. Murphy 1959 Rust-resistant tetraploid derivatives from crosses between Avena abyssinica and A. strigosa. Agron. Jour. 51: 343-345. 